\title{
A Theoretical and Experimental Study of Coplanar Waveguide Shunt Stubs
}

Nihad I. Dib, Member, IEEE, George E. Ponchak, Member, IEEE, and Linda P. B. Katehi, Senior Member, IEEE

\begin{abstract}
A comprehensive theoretical and experimental study of straight and bent coplanar waveguide (CPW) shunt stubs is presented. In the theoretical analysis, the CPW is assumed to be inside a cavity, while, the experiments are performed on open structures. For the analysis of CPW discontinuities with air-bridges, a hybrid technique has been developed which has been validated through extensive theoretical and experimental comparisons. Throughout this study, the effect of the cavity resonances on the behavior of the stubs with and without airbridges is investigated. In addition, the encountered radiation loss due to the discontinuities is evaluated experimentally.
\end{abstract}

\section{INTRODUCTION}

C YOPLANAR WAVEGUIDE (CPW) is rapidly becoming the transmission line of choice in high frequency applications and is successfully competing against the microstrip which has been the primary structure for hybrid and monolithic circuits. Due to many years of microstrip use, a large body of published data and CAD software pertaining to low- and high-frequency microstrip circuit and antenna design has been widely available. On the contrary, models for shielded or open coplanar waveguide circuit design are still under development [1]-[22]. Nevertheless. despite this scarcity of reliable circuit models, CPW has provided an attractive altemative to conventional microstrip lines at high frequencies due to many appealing properties [23]-[31].

While there is no need for via holes in CPW circuits, airbridges are fundamental components required to connect the ground planes for suppression of the coupled slotline mode. In the past few years. there has been several attempis to characterize, theoretically and/or experimentally. CPW discontinuities with air-bridges or bond wires [16]-[22]. The full wave computationally intensive Finite Difference Time Domain technique was used in [17]. [21] to analyze a CPW shunt stub with bond wires and a modified CPW air-bridge $T$ junction. On the other hand, the Finite Difference Frequency Domain method was used in [22] to treat Iwo common types of CPW air-bridges where it was found that the reflection coefficient (or $S_{11}$ ) varies linearly with frequency. This fact suggests that a typical air-bridge can be modeled as a freuency dependent lumped element [16], [18], [19]. [28]. [32]. With this in mind, a hybrid technique has been developed to analyze

Manuscript received Feb. 4. 1992: revised Apr. 27. 1992. This work was supported by the National Science Foundation under contracl EC5-8657951.

N. 1. Dib and L. P. B. Katehi are with the Radiation Lab. Univernity of Michigan. 3228 EECS Building. Ann Arbor. MI 48 109-2127.

G. E. Ponchak is with the XASA Leuis Research Center. 21000 Brookpark

Road, MS-54-5. Cleveland. OH +11.35 .

IEEE Log Number 92040.32.

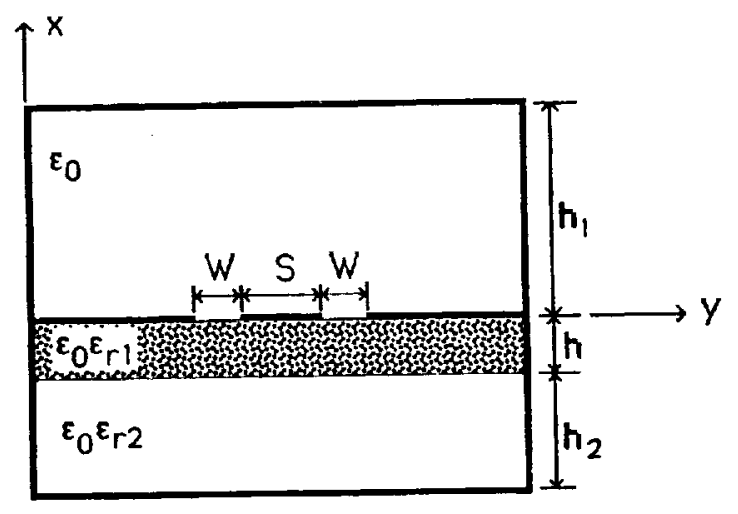

Fig. 1. A cross section of a CPW inside a cavity.

CPW discontinuities with air-bridges. In this technique, the frequency dependent equivalent circuit of the discontinuity, with the air-bridges removed, is derived using the Space Domain Integral Equation (SDIE) method [8], [9]. Then, this equivalent circuit is modified by incorporating the air-bridge parasitic inductance and capacitance which are evaluated using a quasistatic model.

In this paper, the above mentioned hybrid technique is used to study a variety of CPW shunt stub geometries (Fig. 2) and the validity of the model is verified by performing extensive measurements. The scattering parameters of the stubs with and without air-bridges are presented and a very good agreement is found between theoretical and experimental data. In addition, since a shielded structure is assumed in the formulation of the theory, the effect of cavity resonances on the behavior of these stubs is shown. Moreover, the encountered radiation loss in open discontinuities is investigated experimentally.

\section{THEORY}

In the theoretical analysis, the CPW under consideration is assumed to be shielded by a rectangular cavity with perfectly conducting walls as shown in Fig. 1. As pointed out in the introduction, a hybrid technique is used to analyze coplanar waveguide discontinuities with air-bridges. First, the frequency dependent equivalent circuit of the discontinuity, with the air-bridges removed, is derived using the Space Domain Integral Equation (SDIE) method [8], [9]. Then, this equivalent circuit is modified by incorporating the parasitic reactances introduced by the air-bridges. Only the main steps of the SDIE method are given here, since the details can be found in [8], [9].

() 1993 IEEE. Reprinted, with permission, from IEEE Transactions on Microwave Theory and Techniques, vol. 41, no. I, Jan. 1993, pp. 38-44. 


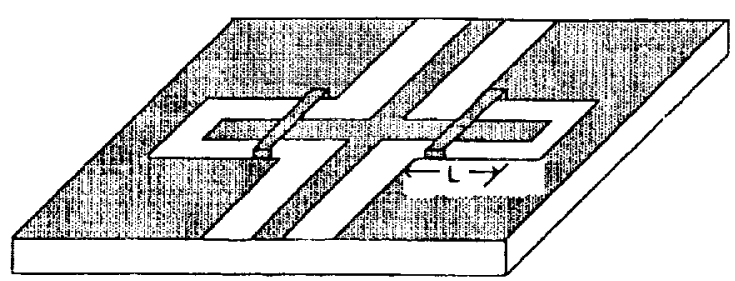

(a)

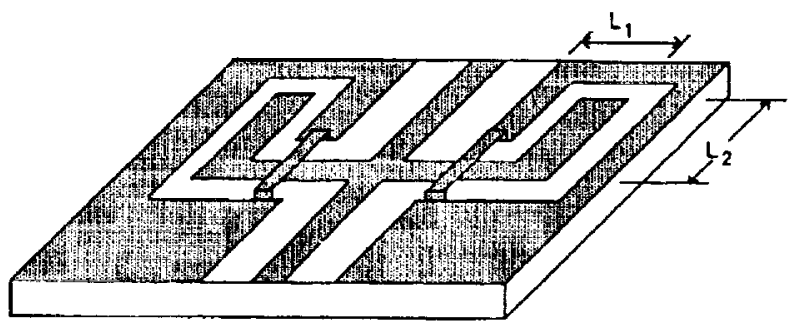

(b)

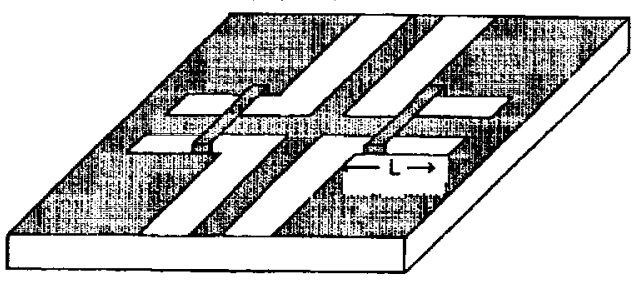

(c)

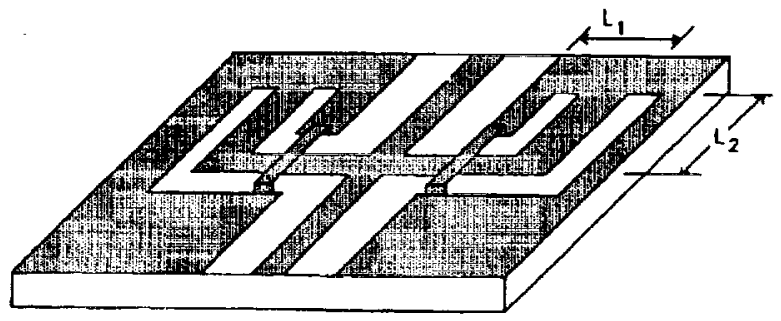

(d)

Fig. 2. Different CPW shunt stubs. (a) Straight open-end CPW stub. (b) Bent open-end CPW stub. (c) Straight shori-end CPW stub. (d) Bent shon-end CPW stub.

\section{A. SDIE Method}

The boundary problem pertinent to any CPW disconinuity may be split into two simpler ones by applying the equivalence principle which introduces an equivalent magnetic current $\bar{M}_{3}$ on the slot apertures [8]-[10]. This surface magnetic current radiates an electromagnetic field in the two waveguide regions (above and below the slots) so that the continuity of the tangential electric field on the surface of the slots is satisfied. The remaining boundary condition to be applied is the continuity of the tangential magnetic field on the surface of the slot apertures which leads to the following integral equation

$$
\tilde{x} \times \int_{S} \int\left[\overline{\bar{G}}_{0}^{h}(\vec{r} / \vec{r})+\overline{\bar{G}}_{1}^{h}(\vec{r} / \vec{r})\right] \cdot \bar{M}_{s}\left(\bar{r}^{\prime}\right) d s^{\prime}=\bar{J}_{s}
$$

with $\overline{\bar{G}}_{0,1}^{k}$ the magnetic field dyadic Green's functions in the two waveguide regions [8], [9] and $\bar{J}_{s}$ an assumed ideal electric current source exciting the coplanar waveguide mode. The integral equation which is formulated here in terms of equivalent magnetic currents flowing on the slot apertures is different from the fullwave technique presented in [1], [5]. [14], where an integral equation in terms of the electric current on the conducting surfaces is formed. The former technique is more appropriate for CPW problems where the ground planes approach the boundary surfaces (open or shielded), while the latter better fits problems with finite size ground conductors.

The integral equation (1) is solved using the Method of Moments [33] where the unknown magnetic current is expanded in terms of rooftop basis functions. Then, Galerkin's method is applied to reduce the above equation to a linear system of equations

$$
\left(\begin{array}{ll}
Y_{y y} & Y_{y z} \\
Y_{z y} & Y_{z z}
\end{array}\right)\left(\begin{array}{l}
V_{y} \\
V_{z}
\end{array}\right)=\left(\begin{array}{c}
I_{z} \\
I_{y}
\end{array}\right)
$$

In the above, $Y_{i j}(i=y, z ; j=y, z)$ represent blocks of the admittance matrix. $V_{i}$ is the vector of unknown $y$ and $z$ magnetic current amplitudes, and $I_{j}$ is the excitation vector which is identically zero everywhere except at the position of the sources. The solution of the matrix equation (2) results in the evaluation of the equivalent magnetic currents and consequently the electric fields on the slots.

In case of isolated CPW structures which are symmetric with respect to the center line, the coupled slotline mode is not excited, and hence, the aperture fields in the feeding lines form standing waves of the fundamental coplanar waveguide mode. Consequently, using the derived electric field, transmission line theory can be utilized to determine the scattering parameters and derive a lumped element equivalent circuit for the discontinuity. In case of asymmetric CPW discontinuities, the derived field in the feeding lines is the sum of the fundamental coplanar and slotline modes each one having its own spatial parameters, and consequently, a special treatment is needed to separate the two modes and derive the scattering parameters of the discontinuity [35].

\section{B. Modeling the Air-Bridges}

Fig. 3(a) shows the equivalent circuit ( $\pi$-model) for the CPW discontinuities shown in Fig. 2 with the air-bridges removed. $X_{1}$ and $X_{2}$ represent the reactances due to the coplanar waveguide mode excited in the CPW stub, while $X_{3}$ is due to the coupled slotline mode [34]. The reference planes at which these reactances are evaluated are at the ends of the uniform feeding lines. It should be noted that in the case of straight stubs, the two reactances $X_{1}$ and $X_{2}$ are equal due to the symmetry of the circuit. Thus, only two independent excitations are needed to evaluate the elements of the equivalent circuit, as opposed to three required in the case of the bent slubs $\left(X_{1} \neq X_{2}\right)[9]$.

Fig. 3(b) show's the new equivalent circuit after taking the air-bridges into consideration. The air-bridges can be modeled as sections of an air-filled microstrip line [16]. [28], and simple formulas can be used to evaluate the parasitic capacitance 


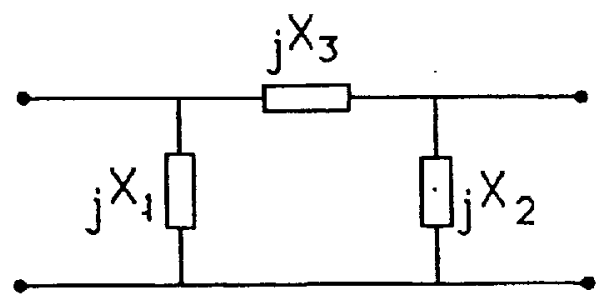

(a)

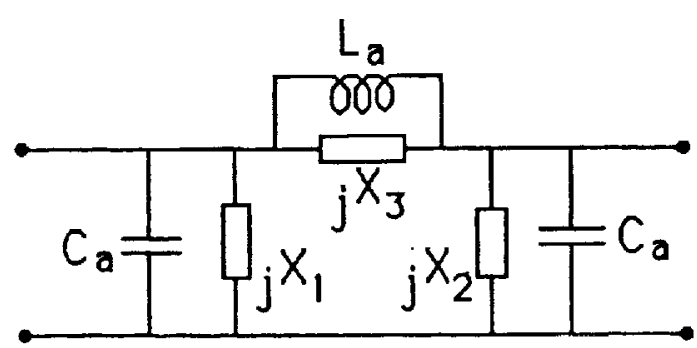

(b)

Fig. 3. (a)Equivalent circuit of the CPW discontinuities shown in Fig. 2 without air-bridges. (b) The modified equivalent circuit after taking the air-bridges into consideration.

$C_{a}$ and inductance $L_{a}$ [34]. Altematively, a parallel plate waveguide model can be employed to evaluate the same parasitic effects. It has been found that the difference in the values of the parasitic reactances as predicted by the two models has a negligible effect on the performance of the circuit. Finally, new scattering parameters are evaluated from the modified equivalent circuit. It should be emphasized that such a hybrid technique assumes that the air-bridges are positioned as close to the cross junction as possible, which is always the case in practice. Moreover, it is worth mentioning that the CPU time required for the evaluation of the scattering parameters (taking into account all the existing physical symmetries) ranges from one to three minutes for each frequency on Apollo Domain 10000 .

\section{RESULTS AND DISCUSSION}

In the numerical results shown here, the considered CPW discontinuities are suspended inside a rectangular cavity, as shown in Fig. 1, with $h=400 \mu \mathrm{m}, \epsilon_{r 1}=13, \epsilon_{r 2}=1$, $S=75 \mu \mathrm{m}, W=50 \mu \mathrm{m}$, and $h_{1}=h_{2}=1.2 \mathrm{~mm}$. The characteristic impedance of such a line is approximately $50 \Omega$. On the other hand, the slots and center conductor of the CPW stubs have equal widths of $25 \mu \mathrm{m}$. In addition, in the case of the open-end stubs, the width of the open-end is $25 \mu \mathrm{m}$. In all examples presented here, the stubs are placed symmetrically at the center of the cavity with length approximately equal to $3 \lambda_{g}$.

The experiments were performed in an open environment with the CPW circuits fabricated on $400 \mu \mathrm{m}$ thick GaAs using lift-off processing. The CPW center strip and ground planes consist of $200 \mathrm{AA}$ of $\mathrm{Cr}$ and $1.5 \mu \mathrm{m}$ of Au. The air-bridges have $10 \mu \mathrm{m}$ square posts and are $14 \mu \mathrm{m}$ wide. The air-bridge thickness and height are $1.0 \mu \mathrm{m}$ and $3.0 \mu \mathrm{m}$, respectively. The

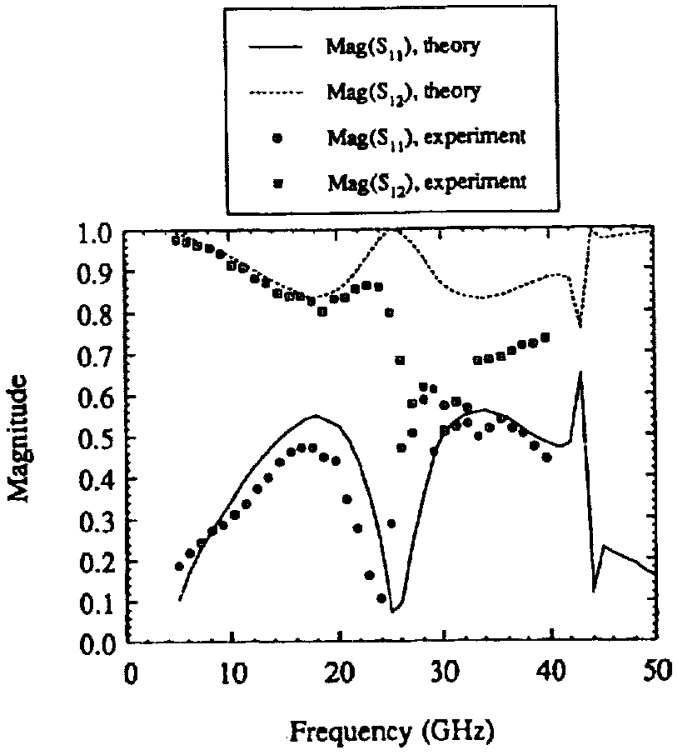

Fig. 4. Scattering parameters of the straight open-end stub without air-bridges $(L=1100 \mu \mathrm{m})$.

GaAs circuit rests on a piece of $3.175 \mathrm{~mm} 5880 \mathrm{RT} /$ duroid which has a dielectric constant of 2.2 .

It will be shown that the theoretical and experimental data agree despite the difference in $\epsilon_{\mathrm{r} 2}$ of the substrate $\left(\epsilon_{\mathrm{r} 2}=1\right.$ versus 2.2 ). This is due to the relatively large thickness of the GaAs substrate layer as compared to $S+2 W$. The choice of $\epsilon_{r 2}=1$ in the theoretical calculations is intended in order to avoid some of the unwanted cavity resonances.

The circuits were tested with an HP 8510 network analyzer and a Cascade probe station. The calibration standards for a TRL calibration were fabricated on the wafer to allow calibration to the reference planes of the CPW stubs. To cover the $5-40 \mathrm{GHz}$ bandwidth, three delay lines were used. The probe positioning on the wafer was determined to be repeatable to within $3 \mu \mathrm{m}$ which creates a maximum error in the phase of $S_{21}$ of $0.76^{\circ}$ at $40 \mathrm{GHz}$.

\section{A. Open-End Shunt Stubs}

Fig. 4 shows the magnitude of the scattering parameters of the straight open-end stub (Fig. 2(a)) of length $L=1100 \mu \mathrm{m}$ with the air-bridges removed as a function of frequency. It is noticed that the theoretical and experimental results agree very well up to the first resonance, after which, discrepancy is noticeable. This is attributed to the fact that no loss is assumed in the theoretical formulation, while, experiments were performed on CPW structures in an open environment. The loss encountered in the measurements is mainly due to radiation by the slotline mode excited in the CPW stubs in the absence of the air-bridges. To understand the unexpected behavior seen between 41 and $45 \mathrm{GHz}$, the reactances $X_{1}$ and $X_{3}$ of the equivalent circuit are plotted in Fig. 5. It can be seen that $X_{1}$, which corresponds to the coplanar mode in the CPW stub, behaves as a real open-end shunt stub. On the other hand, $X_{3}$, which is due to the slotline mode in the CPW stubs, behaves somewhat anomalously between 41 


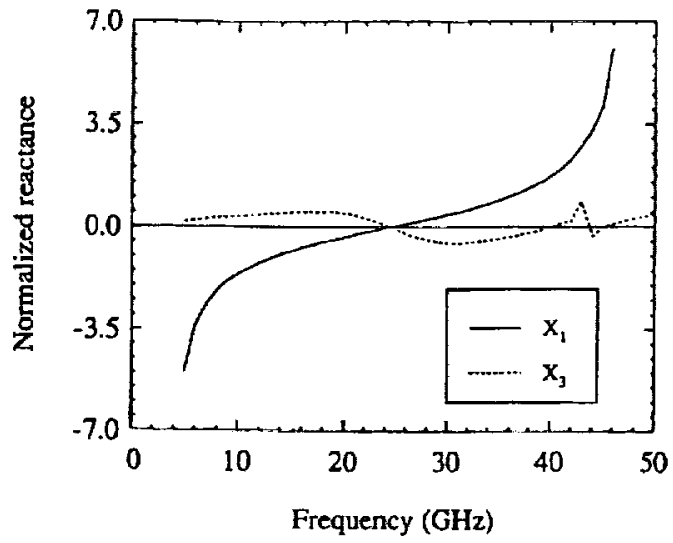

Fig. 5. The normalized reactances of the equivalent circuit for the straight open-end stub of length $L=1100 \mu \mathrm{m}$. The second resonance of $X_{1}$ occurs at approximately $48.2 \mathrm{GHz}$ which is difficult to show on this plot.

and $45 \mathrm{GHz}$. It is found that this behavior is due to a cavity resonance at $43 \mathrm{GHz}$ which corresponds to the $L S M_{121}$ mode excited in the partially filled lower cavity (the cavity width was chosen to be $3.425 \mathrm{~mm}$ ). It is interesting to note that the $L S M_{111}$ cavity mode, which has a resonant frequency of 38 $\mathrm{GHz}$, does not show an observable effect on the stub under consideration. Also, the shunt reactances seem to be unaffected by the $L S M_{121}$ cavity mode.

Fig. 6 shows the scattering parameters (magnitude and phase) of the same straight open-end stub with air-bridges. The good agreement between the theoretical and experimental results validates the developed hybrid technique. As it can be seen, the stub resqnates at nearly $24.5 \mathrm{GHz}$ where the length of the stub is approximately quarer of a coplanar mode wavelength. It can be noticed that the agreement berween the theoretical and experimental data in Fig. 6(a) is much better than the one seen in Fig. 4. This is due to the fact that the airbridges tend to prevent the slotline made from being excited in the CPW stubs which effectively reduces radiation losses encountered in the measurements. In addition, it can be seen that the resonance effect noticed in Fig. 4 has disappeared since $X_{3}$ is shorted by the relatively small air-bridge inductance $L_{a}$. As a result, with the presence of air-bridges, cavity resonances have no effect on the characteristics of a straight stub as long as it is placed symmetrically inside the cavity. One can also notice an anomalous effect at $40 \mathrm{GHz}$ existing in Fig. 6 . A similar effect has been found in [17] for the case of a bent open-end stub. This effect may be due to a resonating slotline mode excited in the stubs beyond the air-bridge.

Fig. 7 shows the magnitude of the scattering parameters for the bent open-end CPW stub (Fig. 2(b)) of mean length $1100 \mu \mathrm{m}$ without air-bridges. In this case, the width of the cavity is taken to be $2 \mathrm{~mm}$. It can be seen that the agreement between theory and experiment is better than that seen in Fig. 4 for the straight stub without air-bridges. Moreover, it has been found that the parallel combination of $X_{1}$ and $X_{2}$ behaves as expected for a real shunt open-end stub (i.e. similar to the variation of $X_{1}$ in Fig. 5). Fig. 8 shows the magnitude of the scattering parameters of the same bent open-end stub with airbridges. It can be seen that the anomalous effect at $40 \mathrm{GHz}$ is

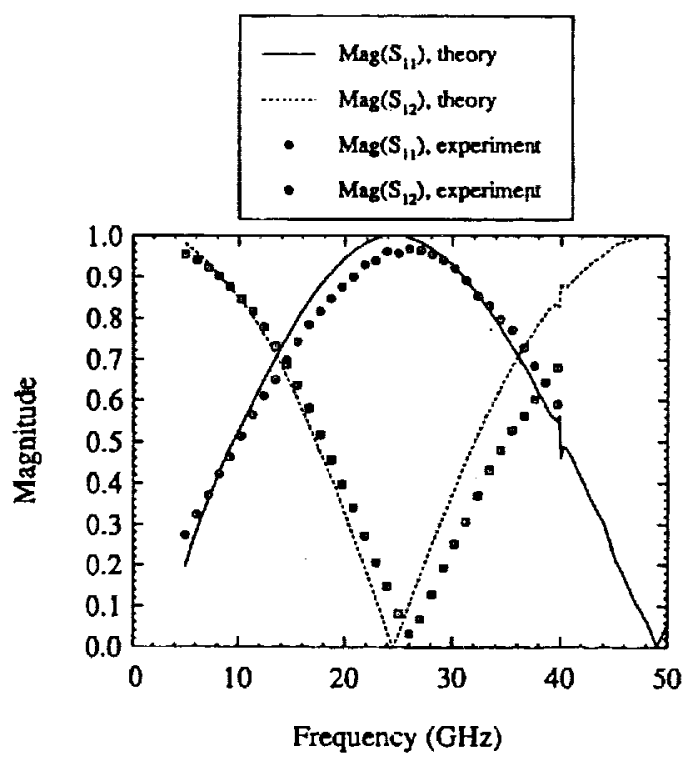

(a)

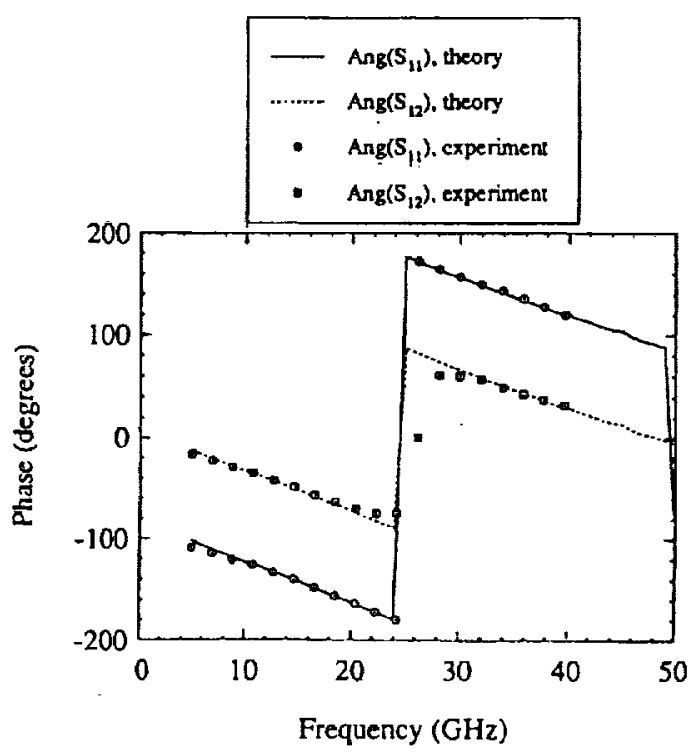

(b)

Fig. 6. Scattering parameters of the straight open-end stub with air-bridges. $(L=1100 \mu \mathrm{m})$.

more pronounced in this case than that in Fig. 6. In addition, the resonant frequency of this bent stub with air-bridges is approximately the same as the one for the straight stub of the same mean length.

\section{B. Short-End Shurt Stubs}

Figs. 9 and 10 show $\operatorname{Mag}\left(S_{11}\right)$ for the straight and bent short-end CPW stubs, respectively, of mean length $L=$ $1100 \mu \mathrm{m}$ with and without air-bridges. It can be noticed that both stubs resonate at approximately $25.5 \mathrm{GHz}$. The same arguments presented above for the open-end stub hold here too. 


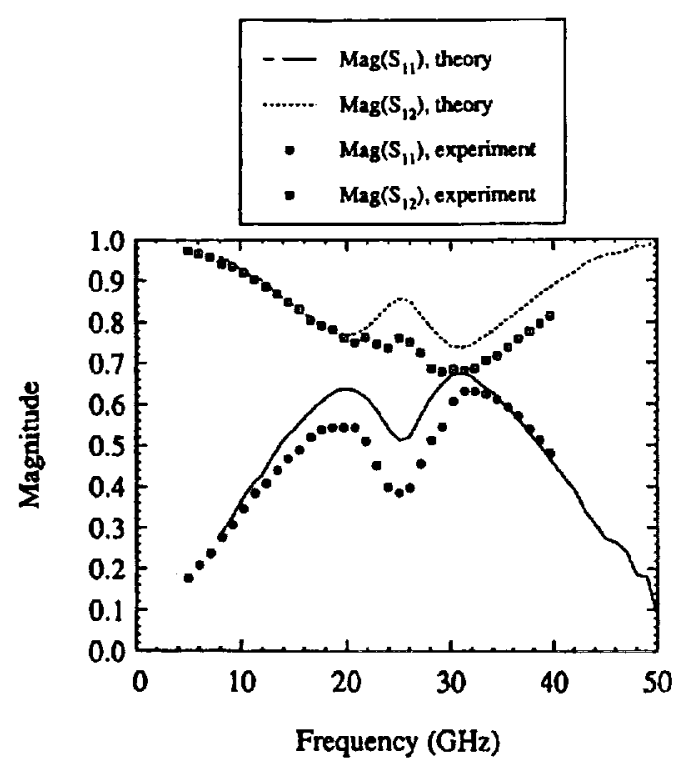

Fig. 7. Scattering parameters of the bent open-end stub without air-bridges. $\left(L_{1}=100 \mu \mathrm{n}, L_{2}=1025 \mu \mathrm{m}\right)$.

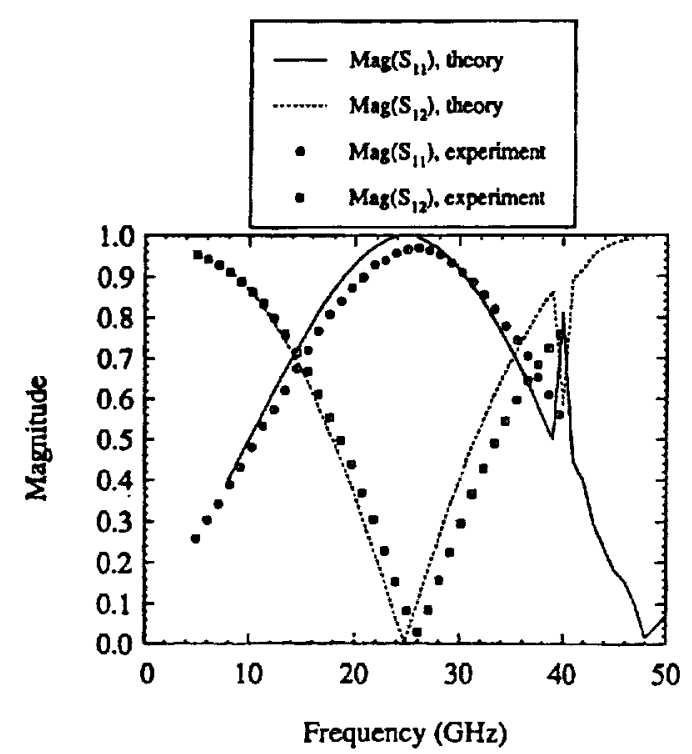

Fig. 8. Scattering parameters of the bent open-end stub with air-bridges. $\left(L_{1}=100 \mu \mathrm{m}, L_{2}=1025 \mu \mathrm{m}\right)$.

It is interesting to note that for all structures containing air-bridges, the measured resonant frequency is larger than the theoretically predicted one. This systematic deviation may be due to the effect of finite metallization thickness $(1.5 \mu \mathrm{m})$ which is neglected in the theoretical analysis. The finite metallization thickness reduces the phase constant [36] and thus increases the stub resonant frequency. EEsof Touchstone has predicted an increase of approximately $1.2 \%$ in the resonant frequency of a section of $\mathrm{CPW}$ of length $1100 \mu \mathrm{m}$ due to the finite conductor thickness.

Since the experiments were performed on open CPW discontinuities, the measured scattering parameters can provide

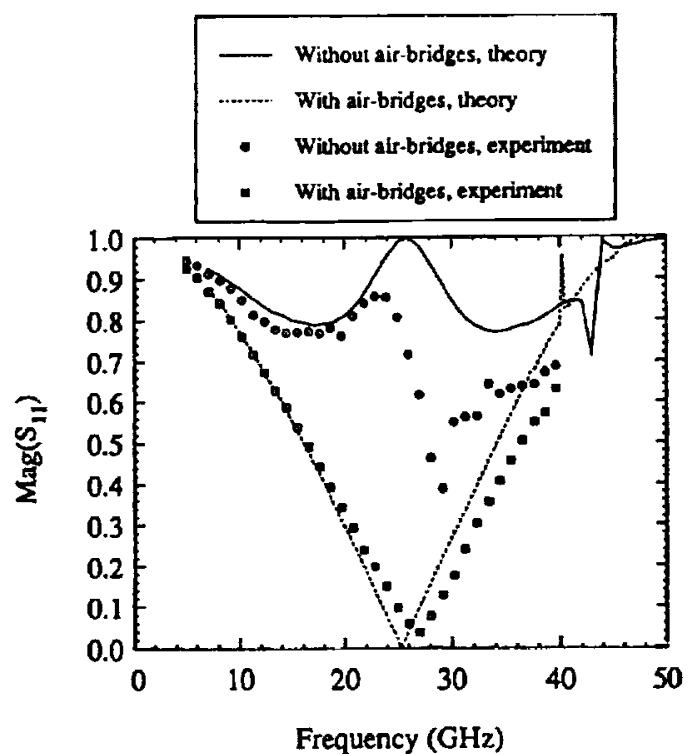

Fig. 9. $\operatorname{Mag}\left(S_{11}\right)$ of the straight shortend stub with and without air-bridges. $(L=1100 \mu \mathrm{m})$.

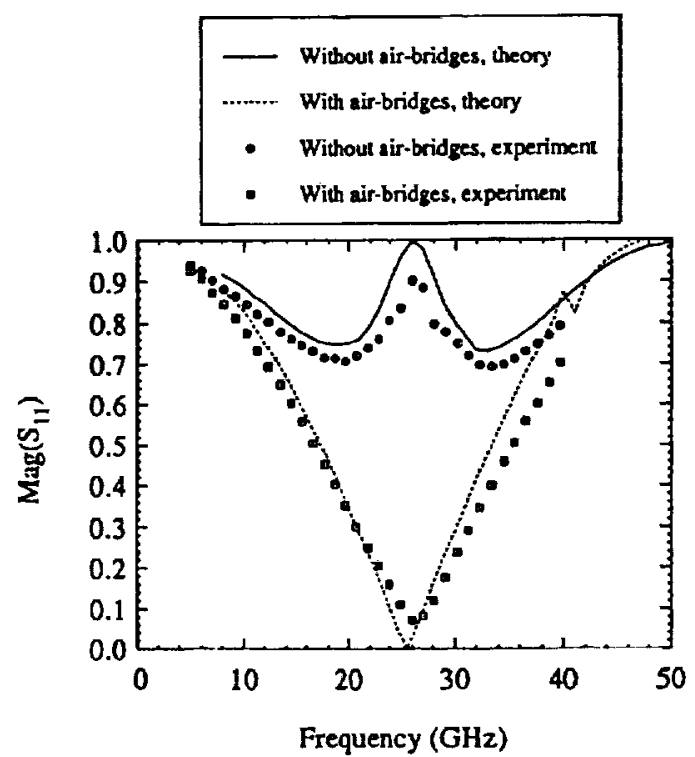

Fig. 10. $\operatorname{Mag}\left(S_{11}\right)$ of the bent shon-end stub with and without air-bridges. ( $L_{1}=100 \mu \mathrm{m}, L_{2}=1025 \mu \mathrm{m}$ ).

the loss factor. This loss factor includes radiation, conductor and dielectric losses. However, since the stubs are all of the same length and printed on the same substrate, a comparison of the loss factor can provide a measure of the radiation loss. Figs. 11 (a) and 12(a) show the loss factor of the short-end and openend stubs without air-bridges, respectively. It is noticed that loss is maximum at the resonant frequency for all stubs, which is similar to what has been found in microstrip stubs [37]. Furthemore, the loss factor for straight stubs is larger than that for bent stubs especially after resonance. This behavior is due to the fact that in the case of bent stubs, the fields radiated by the coupled slotline mode in the two opposing stubs 


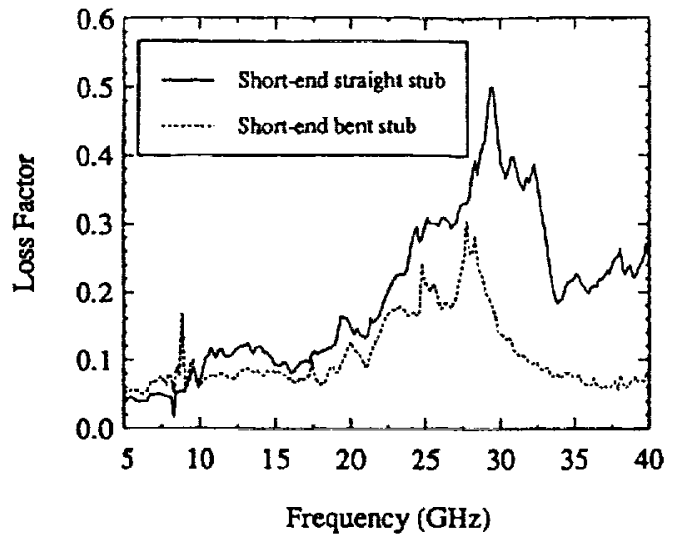

(a)

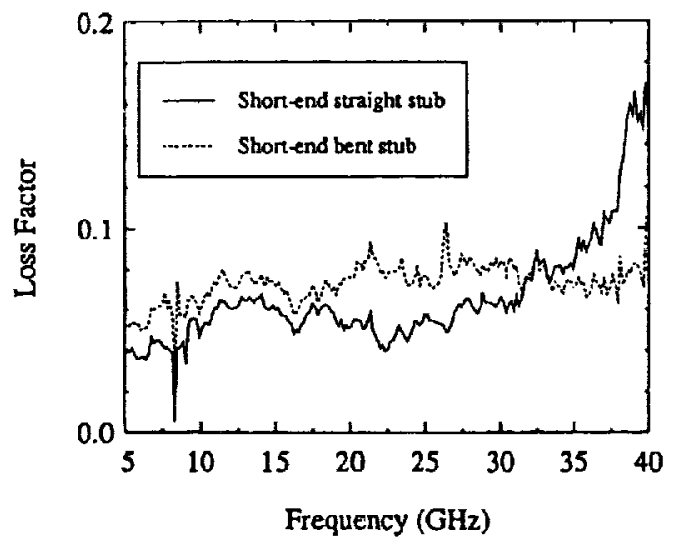

(b)

Fig. 11. The measured loss factor $\left(1-\left|S_{11}\right|^{2}-\left|S_{12}\right|^{2}\right)$ of the shon-end CPW stubs. (a) Without air-bridges. (b) With air-bridges.

partially cancel. This explains why the agreement between the theoretical and experimental results for the bent stubs without air-bridges (Fig. 7 and Fig. 10) is better than that for the straight stubs without air-bridges (Figs. 4 and 9). The loss factor for the stubs with air-bridges is shown in Figs. 11(b) and 12(b). It can be seen that the presence of air-bridges reduces the loss factor appreciably since they short out the radiating coupled slotline mode. However, it is still noted that the straight stubs have increasing radiation loss after the first resonant frequency. Finally, it can be noticed that the difference between the loss factor of the straight and bent stubs (with or without air-bridges) below the resonant frequency is within the experimental error. Thus, no concluding remarks can be made concerning the loss from the two stubs in this region.

\section{CONCLUSIONS}

A comprehensive theoretical and experimental study of CPW shunt stubs has been presented. In the theoretical analysis, the CPW was assumed to be inside a cavity. while, the experiments were performed in an open environment. $A$ hybrid technique has been developed to analyze the CPW discontinuities which proved valid since the results obtained theoretically and experimentally agreed very well. It was found

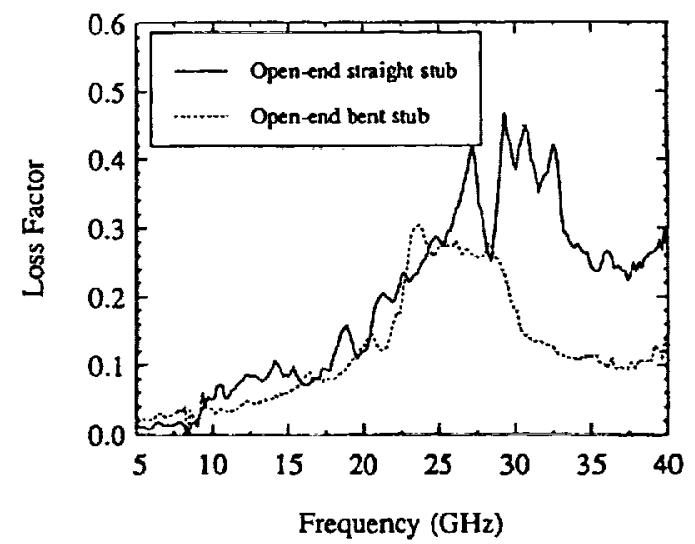

(a)

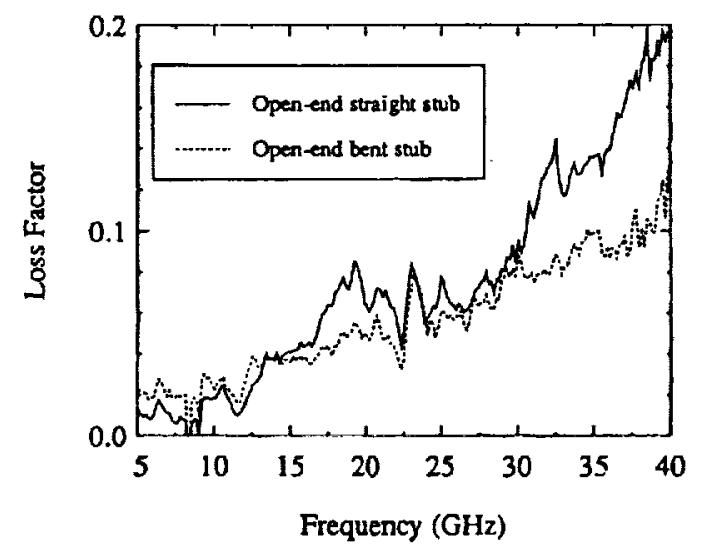

(b)

Fig. 12. The measured loss factor of the openend CPW stubs. (a) Without air-bridges. (b) With air-bridges.

that bent stubs without air-bridges tend to radiate less than straight stubs of the same length. In addition, the effect of the cavity resonances on the behavior of the stubs has been studied. It has been shown through experiments that bent CPW stubs should be used whenever the circuit layout permits to reduce the radiation loss caused by the parasitic coupled slotline mode.

\section{REFERENCES}

[1] R. W. Jackson, "Considerations in the use of coplanar waveguide for millimeter wave integrated circuits," IEEE Trans. Microwave Theory Tech., vol. MTT-34, pp. 1450-1456, Dec. 1986.

[2] R. N. Simons and G. E. Ponchak, "Modeling of some coplanar wave guide discontinuities," IEEE Trans. Microwave Theory and Tech.. vol. 36, pp. 1796-1803, Dec. 1988.

[3] G. Kibuuka, R. Bertenburg, M. Naghed, and I. Wolff, "Coplanar lumped elements and their application in filters on ceramic and gallium arsenide substrates," in Proc. 19th European Microwave Conf. London. Sept. 1989. pp. 656-661.

[4] C. W. Kuo and T. Itoh, "Characterization of the coplanar waveguide step discontinuity using the transverse resonance method," in Proc. $19 \mathrm{th}$ European Microwave Conf., London. Sept. 1989, pp. 662-665.

[5] R. W. Jackson, "Mode conversion at discontinuities in finite- $u$ idıh conductor-backed coplanar waveguide, "IEEE Trans. Microw'ate Theory' Tech. vol. 37, pp. 1582-1589. Oct. 1989.

(6) M. Naghed and I. Wolff, "Equivalent capacilances of coplanar waveguide discontinuities and interdigitated capacitors using a three dimensional finite difference method," IEEE Trans. Microw'ave Theon Tech., vol. 38, pp. 1808-1815, Dec. 1990. 
[7] M. Drissi. V. Fouad Hanna, and J. Citeme, "Analysis of coplanar waveguide radiating end effects of using the integral equation technique," IEEE Trans. Microwave Theory Tech., vol. 39, pp. 112-[16, Jan. 1991.

[8] N. Dib and P, Katehi, "Modeling of shielded CPW discontinuities using the space domain integral equation method (SDIE)," J. Electromugnefic Waves and Applications, pp. 503-523, Apr. 1991.

[9] N. Dib, P. Katehi, G. Ponchak, and R. Simons, "Theoretical and experimental characterization of coplanar waveguide discontinuilies for filter applications," IEEE Trans. Microwave Theory Tech.. vol. 39, pp. 873-882, May 1991.

[10] W. Harokopus and P. Katehi, "Radiation loss from open CPW discontinuities," in 1991 IEEE MTT-S Int. Microwave Symp. Dig., Boston, pp. 743-746.

[11] M. Naghed, M. Rittweger, and I. Wolf, "A new method for the calculation of the equivalent inductances of coplanar waveguide discontinuities," in I99J IEEE MTT-S Int. Microwave Symp. Dig., Bosion, pp. $747-750$

[12] N. Dib and P. Katchi, "The effect of milering on CPW discontinuities," in Proc. 2/st European Microwave Conf. Sept. 1991, pp. 223-228.

[13] U. Mueller, M. Rittweger, and A. Beyer, "Coplanar short considered by the TLM-method with symmetrical condensed modes," in Proc. 21st European Microwave Conf., Sept. 1991, pp. 999-1003.

[14] J. McLean, A. Wieck, K. Ploog, and T. Itoh, "Fullwave analysis of openend discontinuities in coplanar stripline and finite ground plane coplanar waveguide in open environments using a deterministic spectral domain approach," in Proc. 21st European Microwave Conf., Sept. 1991, pp. $1004-1007$.

[15] C. Kuo and T. Itoh, "Characterization of shielded coplanar type Iransmission line junction discontinuities incorporating the finite metallization thickness effect," IEEE Trans. Microweve Theory Tech., vol. 40, pp. 73-80, Jan. 1992.

[16] N. Koster et al, "Investigation of air bridges used for MMC's in CPW rechnique," in Proc. I9th European Microwave Conf., Sept. 1989, pp. 666-671.

[17] M. Rittweger, M. Abdo, and I. Wolff, "Full-Wave analysis of coplanar discontinuities considering three-dimensional bond wires," in 1991 IEEE MTT-S Int. Microwave Symp. Dig., Boston, pp. 465-468.

[18] N. Dib, P. Katehi, and G. Ponchak, "Analysis of shielded CPW discontinuities with ait bridges, in 1991 IEEE MTT-S Int. Microw'ave Symp. Dig., Boston, pp. 469-472.

[19] $R$. Bromme and $R$. Jansen, "Systematic investigation of $C P W$ MIC/MMIC structures using strip/slot 3D electromagnetic simultor," in 1991 IEEE MTT-S Int. Microwave Symp. Dig.. Boston, pp. 1081-1084.

[20] T. Becks and I. Wolff, "Calculation of three-dimensional passive structures including bond-wires, via-holes and air-bridges using the spectral domain analysis method," in Proc. 21 st European Microw'ne Conf. Sept. 1991, Pp. 571-576.

[21] M. Rittweger, N. Koster, S. Koblowski, R. Bentenburg, S. Heinen. and I Wolff, "Full-wave analysis of a modified coplanar air bridge $T$-junction," in Proc. 21 st European Microwave Conf., Sept. 1991, pp. $993-998$.

[22] $\mathrm{K}$. Beilenhoff, W. Heinrich, and $\mathrm{H}$. Hartnagel, "The scattering behavior of air bridges in coplanar MMIC's," in Proc. of 2Ist European Microwave Conf. Sept. 1991. pp. 1131-1135.

[23] C. P.' Wen, "Coplanar waveguide: A surface strip transmission line suitable for nonreciprocal gyromagnetic device applications." IEEE Trans. Microwave Theory Tech., vol. MTT-17. pp. 1087-1090. Dec. 1969

[24] M. Houdart, "Coplanar lines: Application to broadband microwave integrated circuits," in Proc. 6th European Microwave Conf.. Rome, 1976. pp. 49-53.

[25] P. A. Holder, "X-band microwave integrated circuits using slollines and coplanar waveguide," Radio Electronics Engineering. vol. 48. pp. 38-42, Jan./Feb. 1978.

[26] R. N. Simons, "Propagation characteristics of some novel coplanar waveguide transmission lines on GaAs at MM-wave frequencies." in Proc. 1986 Conf. Millimeter Wave/Microviave Measuremenrs and Standards for Miniaturized Systems, Alabama, Nov, 6-7, 1986

[27] G. Ghione and C. U. Naldi, "Coplanar waveguides for MMIC applications: Effect of upper shielding, conductor backing, finite-extent ground planes, and line-to-line coupling." IEEE Trans. Microware Theon" Tech., vol. MTT-35, pp. 260-267 Mar. 1987.

[28] T. Hirota, Y. Tarusawa, and H. Ogawa, "Uniplanar MMIC hybrids-A proposed new MMIC structure," IEEE Trans. of Microwave Theor Tech. vol. MTT-35, pp. 576-581, June 1987.

[29] M. Muraguchi et al., "Uniplanar MMIC's and their applications." IEEE Trans. of Microwave Theony Tech., vol. MTT-36, pp. 1896-1990. Dec. 1988

[30] M. Riaziat, E. Par, G. Zdasiuk, S. Bandy, and M. Glenn, "Mnnolithic millimeter wave CPW circuits," in 1989 IEEE MTT S Int. Microwra'e Symp. Dig.. Long Beach, CA, pp. 525-528.

[31] D. Leistner, W. Schmid, and G. Eggers. "Application of coplanar waveguide microwave integrated circuils at $\mathrm{C}$ - and $\mathrm{Ku}$-band frequencies." in Proc. 20th European Microurave Conf.. Sept. 1990, pp. 1021-1026.

[32] "CAD oriented numerical techniques for the analysis of microwave and MM-wave transmission-line discontinuities and junctions," in Pror. Int. Workshop of the German IEEE MTT/AP Chapter, Stuttgant. Sept. 13. 1991.

[33] R. F. Harrington, Field Computation By Moment Methods. New York: Macmillan, 1968.

[34] K. C. Gupta, R. Garg, and I. J. Bahl. Microstrip Lines and Slotlines Dedham, MA: Anech House, 1979.

[35] N. Dib and P. Katehi, "Characterization of nonsymmetric coplanar waveguide discontinuities," in 1992 IEEE MTT -S Int. Microwave Symp. Dig., Albuquerque, NM, June 1-5.

[36] K. Koshiii, E. Shu, and S. Miki, "An analysis of coplanar waveguide with finite conductor thickness-Computation and measurement of characteristic impedance," Electronics and Communications in Japan. vol. 64-B, no. 8, pp. 69-78, 1981

[37] W. P. Harokopus and P. B. Katehi. "Characterization of microstrip discontinuities on multilayer dielectric substrates including radiation losses," IEEE Trans. Microwave Theon. Tech., vol. 37. pp. 2058-2065. Dec. 1989.

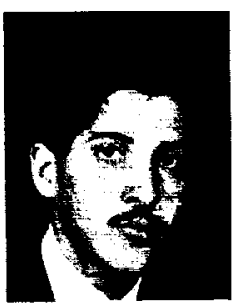

Nihad Dib received the B.Sc. and M.Sc. degrees in electrical engineering from Kuwail University in 1985 and 1987, respectively.

He then worked as a Laboratory Engineer in the ECF. Deparment at Kuwait University for two years. He has been with the Radiation Laboratory. University of Michigan, since Sept. 1988, where he obtained his Ph.D. degree in October 1992.

Mr. Dib was a recipient of a Pre-Doctoral Rackham Fellowship. University of Michigan, during the academic year 1991-1992. His research deals mainly with the consisuction of CAD prozrams for the analysis of Coplanar Waveguide structures and other prinied lines.

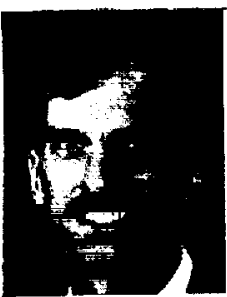

George Ponchak received the B.E.E. degree from Cleveland, State Lniversity, Cleveland, OH. in 1983 and the M.S.E.E. from Case Westem Reserve University, Cleveland. $\mathrm{OH}$ in 1987.

He joined the NASA Lewis Research Center. Cleveland, in July 1983 as a member of the Space Communications Division. Since joining NASA he has been engaged in research in solid-state rechnology development, transmission lines, and monolithic microwave iniegrated circuits (MMIC's). He is currently pursuing his Ph.D. degree with the University of Michigan.

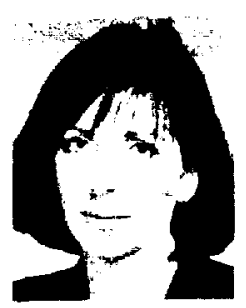

Linda P. B. Katehi (S'81-M'84-SM'84) received the B.S.E.E. degrec from the National Technical University of Athens, Greece, in 1977 and the M.S.E.E. and Ph.D. degrees from the University of Califomia. Los Angeles, in 1981 and 1984. respectively.

In Sept. 1984 she joined the faculty of the EECS Department of the University of Michigan. Ann Arbor. Since then. she has been involved in the modeling and computer-aided design of millimeter and near-millimeter wave monolithic circuits and antennas.

In 1984 Dr. Katehi received the W. P. King Award and in 1985 the S. A. Scheikunoff Award from the Antennas and Propagation Society. In 1987 she received an NSF Presidential Young Investigator Award and an URSI Young Sciencist Fellowship. She is a member of Sigma Xi and URSI Commision D. 
